week post-diagnosis than salaried survivors. The self-employed had received less financial compensation when absent from work post-cancer, and more self-employed, than salaried, survivors reported a negative financial change due to the cancer. There were differences between self-employed and salaried survivors in physical job demands, work ability and quality-oflife but the direction and magnitude of the differences differed across countries.

Discussion Self-employed and salaried CS differ when it comes to RTW-related outcomes, but the patterns vary between countries. Support should be provides to self-employed survivors to help them balance their health needs with those of their business.

\section{FULL-SHIFT HAND-ARM VIBRATION MEASUREMENTS AMONG ROCK DRILLERS}

1,2,3Thomas Clemm*, ${ }^{3}$ Karl-Christian Nordby, ${ }^{1,3}$ Bente Ulvestad, 'Margun Dahle, ${ }^{4}$ Karl Færden, ${ }^{2}$ Magne Bråtveit. ${ }^{1}$ Occupational Health Department, Mesta AS, Bergen, Norway; ${ }^{2}$ Department of Global Public Health and Primary Care, University of Bergen, Norway; ${ }^{3}$ National Institute of Occupational Health, Oslo, Norway; ${ }^{4}$ Department of Occupational medicine, Oslo University Hospital, Oslo, Norway

10.1136/oemed-2018-ICOHabstracts. 1489

Introduction Rock drills expose workers to high levels of hand-arm vibration, and extensive use of these tools give an increased risk of hand-arm vibration syndrome. Hand-arm vibration exposure can be difficult to estimate by using the task-based method because of an intermittent exposure pattern and changing working conditions throughout the work shift. New advances in measurement technology make it possible to perform full-shift measurements at the workplace.

Methods Hand-arm vibration exposure for rock drillers/rock face stabilisers in Norway was assessed by full-shift field measurements with Svantek SV103 vibration metres on both right and left hand simultaneously.

Result The mean daily vibration exposure for the rock drillers was $4.9 \mathrm{~m} / \mathrm{s}^{2}(\mathrm{~A} 8$ ) (range 2.7-8.8) for the right hand and 4.4 $\mathrm{m} / \mathrm{s}^{2}$ (A8) (1.0-7.0) for the left hand, based on 17 full-shift measurements. The mean exposure magnitude from the tools was $14.0 \mathrm{~m} / \mathrm{s}^{2}(9.2-20.0)$. For 12 of the 17 measurements the exposure was highest on the dominant hand.

Discussion The full-shift method was practical to implement in the field measurements, and should be considered as an alternative to the task based method. This method has the potential to reduce the uncertainties associated with unpredictable changes in exposure like changing hardness of the rock. The daily exposure to hand-arm vibrations for the rock drillers was high compared to the occupational exposure limit. Thus, implementation of efficient strategies to reduce vibration exposure is important.

\section{OCCUPATIONAL HEALTH AND THE SOCIAL DETERMINANTS OF HEALTH: IDENTIFYING THE ETHICAL ISSUES}

Jacques Tamin*. Honorary Senior Lecturer in Occupational Medicine, COEH, University of Manchester

10.1136/oemed-2018-ICOHabstracts. 1490
Introduction 'Job security increases health, wellbeing and job satisfaction. Higher rates of unemployment cause more illness and premature death'. Encouraging individuals to be at work can be beneficial, but it also raises questions such as: Do the socially disadvantaged have access to opportunities to improve their health? Do they have fair access to health-enhancing 'good' work? OH professionals can have an important influence in matters of health and work, both at 'front line' and policy levels. This paper identifies the ethical issues that arise in the wider social determinants of health (SDOH) discourse, from an $\mathrm{OH}$ perspective.

Methods An applied ethics analytical approach was used to examine the relationship between $\mathrm{OH}$ and $\mathrm{SDOH}$, especially in terms of worklessness arising from ill-health. The capability approach as a theory of justice was used. Specifically, a concept of health justice when one is unable to work through illhealth or disability was explored.

Results Areas of ethical concern:

- The medicalisation of the ill-health assessment process, whereas societal factors are ignored.

- The extension of 'responsibilisation', i.e. making individuals responsible for their ability to work as well as for their health.

- Ethical tensions for $\mathrm{OH}$ practitioners when their relationship with the worker may not be the traditional 'doctor-patient' one.

Discussion Unemployment, job insecurity and sickness absence are serious problems, impacting on the health of individuals and society, and a financial burden to employers and the State. However, although it may be desirable for individuals to be in employment to improve their health, there is also a danger that those unable to work become stigmatised. So, 'tackling' these problems should be done in fair and ethical ways. A first step is identifying the ethical issues.

\section{MUSCULAR ACTIVATION IN VIBRATION PERTURBED HUMAN WALKING AND MODELLING}

${ }^{1}$ Francesco Felici, ${ }^{1}$ lenia Bazzucchi, ${ }^{2}$ Enrico Marchetti, ${ }^{3}$ Marco Tarabini, ${ }^{2}$ Angelo Tirabasso, ${ }^{2}$ Raoul Di Giovanni, ${ }^{2}$ Alessandro Lunghi, ${ }^{2}$ Floriana Sacco, ${ }^{1}$ Cristian leno, ${ }^{4}$ Luigi Fattorini. ${ }^{1}$ University Foro Italico of Roma, Department of Movement, Human and Health Sciences; ${ }^{2}$ Italian National Institute for Insurance against Accidents at Work, Department of medicine, epidemiology, workplace and environmental hygiene, Monte Porzio Catone (RM), Italy; ${ }^{3}$ Politecnico di Milano, Department of Mechanics, Polo Territoriale di Lecco; ${ }^{4}$ Sapienza University of Roma, Department of Physiology and Pharmacology 'V. Erspamer'

10.1136/oemed-2018-ICOHabstracts. 1491

Introduction Walking on vibrating floor causes a complex exposure pattern and the superimposition of walk and vibration may induce early muscular fatigue. ${ }^{1}$ The problem is relevant is many field, as sea platform or railway transports. The present study studies the leg muscular activation and stride phases during walking under vibration to derive a muscle model in these circumstances.

Methods Subjects walked on a treadmill positioned on a 6DOF vibrating table. Vibration was imposed at four frequencies $(4,8,12,16 \mathrm{~Hz})$ along vertical and transversal direction. The walking speed was set at $1.25 \mathrm{~m} / \mathrm{s}$. Surface electromyography (sEMG) of four muscles was recorded. Stride phases were recorded using accelerometers and stride length was 
calculated. Acceleration signals were acquired in several body districts (foot, knee and hip). All measurements were related to the walking condition without the vibration.

Result Preliminary results showed that vibration does not affect stride length and step phases. The muscular activation patterns exhibit frequency related modification, in terms of sEMG bursts amplitude and timing. There is a linear correlation between $8 \mathrm{~Hz}$ frequency and muscular activation.

Discussion Transmitted vibration triggers a tonic vibration reflex (TVR) that is related to mechanical frequencies. ${ }^{2}$ TVR is also related to the motor task because of the mechanical coupling between vibrator and biological apparatus. ${ }^{3}$ These facts could explain the modifications in leg muscle activation revealed with sEMG.

\section{REFERENCES}

1. Fattorini L, Tirabasso A, Lunghi A, Di Giovanni R, Sacco F, Marchetti E. Muscular forearm activation in hand-grip tasks with superimposition of mechanical vibrations. J Electromyogr Kinesiol 2016;26:143-148.

2. Eklund $G$, Hagbarth KE. Normal variability of tonic vibration reflexes in man. Exp Neurol 1966;16:80-92.

3. Fattorini L, Tirabasso A, Lunghi A, Di Giovanni R, Sacco F, Marchetti E. Muscular synchronisation and hand-arm fatigue. Int I Ind Ergon 2017.

\section{HEARING LOSS INDUCED BY ENVIRONMENTAL NOISE IN MEXICAN ADULTS FROM MEXICO CITY}

${ }^{1} \mathrm{CA}$ Juárez ${ }^{*},{ }^{2} \mathrm{~A}$ Torres, ${ }^{1} \mathrm{G}$ Aguilar, ${ }^{3} \mathrm{~W}$ Hinojos, ${ }^{4} \mathrm{PE}$ Ravelo, ${ }^{1} \mathrm{D}$ Fierro, ${ }^{1} \mathrm{LA}$ Trejo, ${ }^{1} \mathrm{~A}$ Cabello, ${ }^{1} \mathrm{O}$ Trujillo, ${ }^{1} \mathrm{C}$ Madrigal, ${ }^{5} \mathrm{C}$ Jimenez. ${ }^{1}$ Occupational Health Research Unit, IMSS Mexico City, Mexico; ${ }^{2}$ Audiology Department Hospital of Specialties, IMSS Mexico City, Mexico; ${ }^{3}$ Audiology Department, Regional Hospital 1, Morelos Unit, Chihuahua, Mexico; ${ }^{4}$ Occupational nurse, Mexico City, Mexico; ${ }^{5}$ Hospital of traumatology Clinical Analysis Laboratory IMSS Mexico City, Mexico

\subsection{6/oemed-2018-ICOHabstracts. 1492}

Introduction The noise affects the individual social integration by damaging their hearing.

Aim The aim of the study was to measure the average hearing threshold (UAP) and its determinants in a group of Mexican adults in Mexico City.

Methods We studied 177 adults of both sexes. We excluded those exposed to industrial noise and organic solvents, as well as those who suffered brain trauma with loss of consciousness, frequent respiratory infections and otitis media. We measured the auditory threshold by tonal audiometry $(125-8000 \mathrm{~Hz})$. The UAP was modelled with robust multiple linear regression. Results $57.3 \%$ (101) were men, with a mean age of 29 (9 16-61] years and 43\% (76) women aged 30 (9 17-54]. There was appreciated a fall at the auditory threshold frequencies 3, 4 and $6 \mathrm{KHz}$ (notch) and recovery to the $8 \mathrm{kHz}$, by sex, age and terciles in both ears. The $4 \mathrm{kHz}$ showed hearing loss of $\beta=2.96 \mathrm{~dB} \quad(\mathrm{p}=0.005)$ by urban travel time $>40$ minutes/day in men $\beta=2.6 \mathrm{~dB} \quad(\mathrm{p}=0.009)$, by categories of age: $25-34$ years $\beta=2.2 \mathrm{~dB}(\mathrm{p}=0.070), 35-44$ years $\beta=5.2 \mathrm{~dB}(\mathrm{p}=0.001)$ and $45-61$ years $\beta=8.3 \mathrm{~dB}(\mathrm{p}<0.001)$.

Discussion The indentation suggests a hearing loss similar to the first stage of the noise-induced hearing damage. It is likely his relationship to the ambient noise of Mexico City.

\section{NEW RISK CONCEPTS IN THE NORWEGIAN OIL AND GAS INDUSTRY AND ITS IMPACT ON NOISE RISK ASSESSMENT}

HT Smedbold*. Teamleder Health and Working Environment, Proactima AS, Norway

10.1136/oemed-2018-ICOHabstracts. 1493

The Norwegian Petroleum Safety Authority has been defined risk as the consequences of an activities, with associated uncertainty. This concept applies on both quantitative risk assessment (with focus on large accidents) where it has been developed and the field of occupational hygiene and acoustics.

This presentation will discuss its impact on occupational health risk assessment in general and on noise risk assessment more specific and gives examples of how this new concept has influenced our work.

\section{Women, Health and Work}

\section{MAINSTREAMING GENDER INTO OCCUPATIONAL SAFETY AND HEALTH (OSH) PRACTICE}

SM Copsey* Elke Schneider. European Agency for Safety and Health at Work (EU-OSHA)

\subsection{6/oemed-2018-ICOHabstracts. 1494}

Introduction Women and men are different, and the jobs they do, their working conditions and circumstances and how society treats them are different, affecting the occupational risks they face: a gender-sensitive prevention approach is required. However, gender mainstreaming and taking a gender-sensitive approach are not always well understood in OSH. Practice needs to be exchanged and experiences shared in order to debunk some of the myths and barriers. This project researched examples of policies, programmes and practices from across the $\mathrm{EU}$ and worldwide to illustrate gender approaches in OSH.

Methods The cases cover approaches by national and intermediary organisations and gender-sensitive approaches to $\mathrm{OSH}$ in the workplace. Detailed descriptions of a range of cases were made, covering the development process and what was achieved. Brief summaries of additional examples were made. The cases were analysed for success factors, challenges, drivers and transferability.

Results The cases were varied, covering: integrating gender mainstreaming into organisations' planning, administration and daily working practices; developing methods and tools to promote gender mainstreaming; facilitating working conditions suitable for both women and men, including both health and human resources management; the reconciliation of work and family life and thereby promoting better work-life balance; ensuring women are encouraged and supported in working in male-dominated professions; designing and promoting personal protective equipment (PPE) for women; conducting awarenessraising campaigns on health.

Discussion Men and women benefit when gender differences are recognised and are addressed in OSH. The report shows 